\title{
Trans-semilunar valve hybrid technique for Amplatzer device closure of complex muscular ventricular septal defects during arterial switch operation
}

\author{
Surendranath R. Veeram Reddy, MD, Javier E. Brenes, MD, and Joseph M. Forbess, MD, Dallas, Tex
}

Multiple muscular ventricular septal defects (mVSDs) in patients with d-transposition of the great arteries (dTGA) present a unique challenge. In neonates with dTGA and remote mVSDs not suitable for patch closure, various single-stage or staged treatment strategies are used. We present a neonate with dTGA and complex multiple mVSDs who underwent a novel single-stage trans-semilunar valve hybrid technique for device closure of multiple mVSDs followed by the arterial switch operation.

\section{CLINICAL SUMMARY}

An 11-day-old neonate with dTGA and multiple mVSDs was taken to the operating room for a single-stage hybrid procedure: intraoperative device closure of mVSDs and arterial switch operation. Echocardiography showed complex mVSDs with 1 large apical mVSD and an adjacent additional tunnel-like apical $\mathrm{mVSD}$ at the left ventricular (LV) apex with multiple openings on the right ventricle (RV) side caused by dense RV muscle trabeculations (Figure 1).

\section{TECHNIQUE}

On cardiopulmonary bypass (CPB), the patent ductus arteriosus was ligated and divided. An attempt to visualize the apical mVSDs via a right atriotomy was unsuccessful. After transection of the great vessels, the ventricular septum was visualized from the anterior (aortic) and posterior (pulmonary) semilunar valves. A large tunnel-shaped opening of the mVSD was best seen from the anterior semilunar valve. A right-angle clamp, advanced from the anterior semilunar valve across the mVSD into the LV, was used to snare a soft-tip wire, advanced from the posterior semilunar valve to the LV. The wire was exteriorized across the anterior semilunar valve (Figure 2, B)

\footnotetext{
From the University of Texas Southwestern Medical Center, Dallas, Tex. Disclosures: Authors have nothing to disclose with regard to commercial support. Received for publication Feb 18, 2013; accepted for publication March 18, 2013; available ahead of print April 11, 2013.

Address for reprints: Surendranath R. Veeram Reddy, MD, University of Texas Southwestern Medical Center, Pediatrics, 1935 Medical District Drive, Heart Center, Children's Medical Center, Dallas, TX 75235 (E-mail: suren.reddy@childrens. com).

J Thorac Cardiovasc Surg 2013;146:483-5

$0022-5223 / \$ 36.00$

Copyright (c) 2013 by The American Association for Thoracic Surgery http://dx.doi.org/10.1016/j.jtcvs.2013.03.019
}

and exchanged for a stiffer J-tip wire, with the J-tip secured in the LV apex with a forcep from the posterior semilunar valve. A 7F sheath was advanced from the anterior semilunar valve, across the mVSD tunnel to the LV apex. The tip of the sheath was gently secured in place with a forcep from the posterior semilunar valve. An 8/6 Amplatzer Duct Occluder (ADO; St Jude Medical, Inc, St Paul, Minn) was advanced through the short sheath to the LV apex. The aortic retention skirt (12 $\mathrm{mm}$ in diameter) was deployed on the LV side under direct vision without capturing the mitral valve apparatus (Figure 2, $C)$. The sheath was gently pulled against the septum, and the device was deployed across the mVSD. Attention was then directed through the anterior semilunar valve, and the ADO device was seen wedged in the mVSD tunnel on the RV aspect. The device was released, and by working through the tricuspid valve, a single suture was placed to secure the device to the RV septum (Figure 2, $D)$. The tricuspid and mitral valves were undisturbed, and the semilunar valves were well preserved. Next, an arterial switch procedure and a Lecompte maneuver were performed. A postoperative echocardiogram showed stable device position with no residual ventricular septal defect shunt (Figure 1,C).

\section{DISCUSSION}

Successful closure of complex mVSDs is a surgical challenge. Device closure of mVSDs has been increasingly proposed as a viable alternative to conventional techniques. Multiple authors have published their experience with staged treatment strategies for device closure of mVSDs in patients with dTGA. ${ }^{1-3}$ Neukamm and colleagues ${ }^{4}$ described a hybrid transatrial strategy for device closure of mVSDs with an ADO. Baird and colleagues $^{5}$ described the superior left atrial hybrid approach under CPB for closure of mVSDs with the ADO device in a patient with dTGA. To our knowledge, the trans-semilunar valve hybrid surgical technique for device closure of complex multiple apical mVSDs with an ADO has never been described. This approach may be beneficial in patients with a complex tunnel-like mVSD, from the LV apex extending anteriorly to the RV infundibulum, who require open surgery for associated heart defects. The advantages of the trans-semilunar valve 

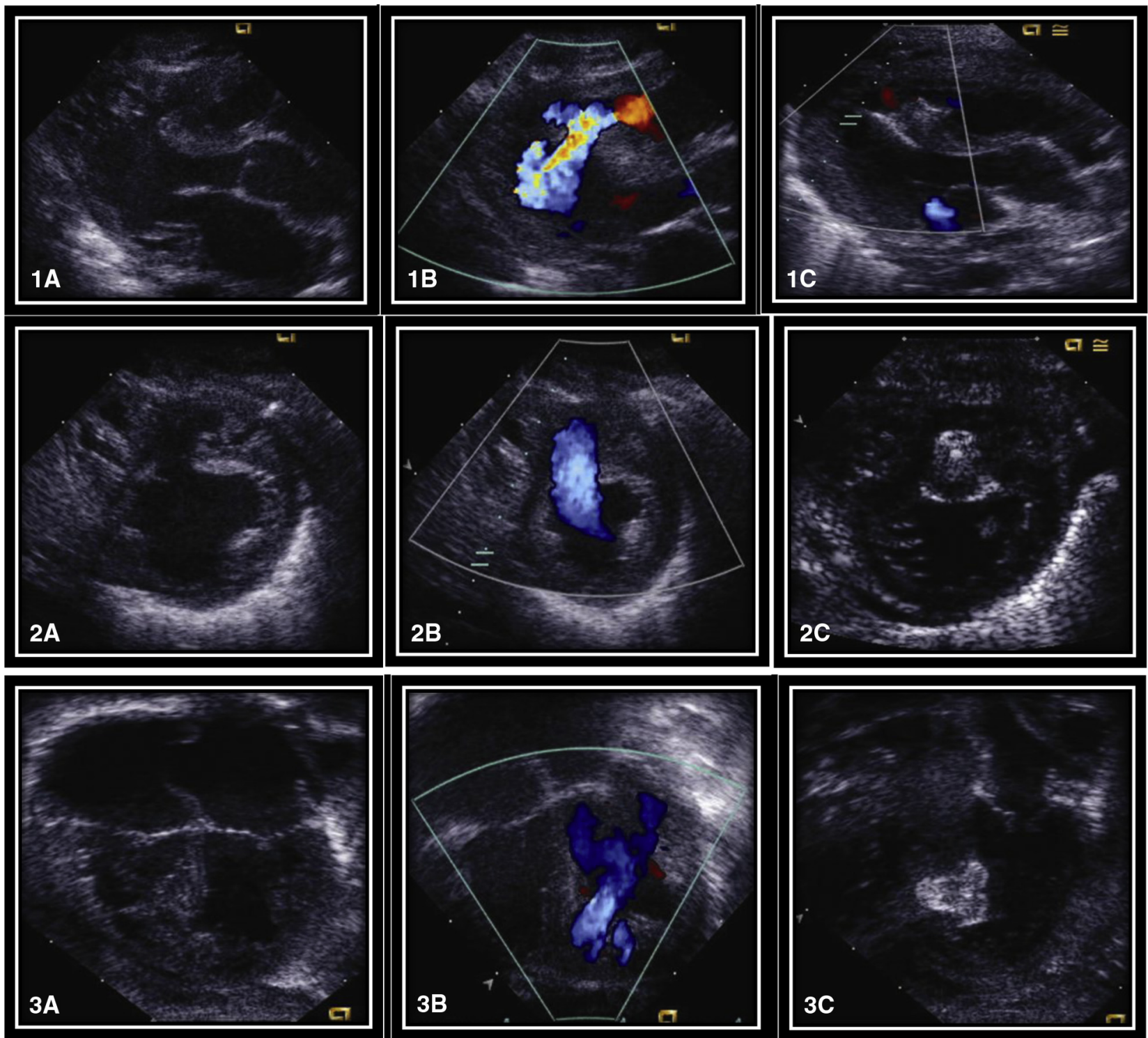

FIGURE 1. Complex apical mVSDs shown in different echocardiogram projections. Row 1: parasternal long-axis view: complex apical mVSD without color (A), with color (B), and after device closure (C). Row 2: parasternal short-axis view: complex apical mVSD without color (A), with color (B), and after device closure (C). Row 3: apical 4-chamber view: complex apical mVSD without color (A), with color (B), and after device closure (C).

hybrid approach for mVSD device closure include avoidance of left atriotomy, right or left ventriculotomy, and any associated muscle resection. The disadvantage of needing a sternotomy and CPB with this approach does not apply to patients who require open surgery to correct other associated heart defects.

\section{CONCLUSIONS}

Selecting the appropriate size and type of device is an important step in this hybrid strategy. The patent ductus arteriosus ADO devices appear to be an optimal anatomic match for the tunnel-like apical mVSDs. The relatively larger aortic retention skirt of the ADO devices also offers an additional advantage of occluding other adjacent smaller mVSDs. The authors emphasize the importance of preoperative imaging for accurate delineation of the location, number, shape, and size of the mVSDs and clear appreciation of understanding the adjacent anatomy and proposed repair of the associated heart defects. This hybrid strategy also highlights the importance of collaboration between cardiothoracic surgeons and interventional cardiologists in the management of such challenging heart defects. 


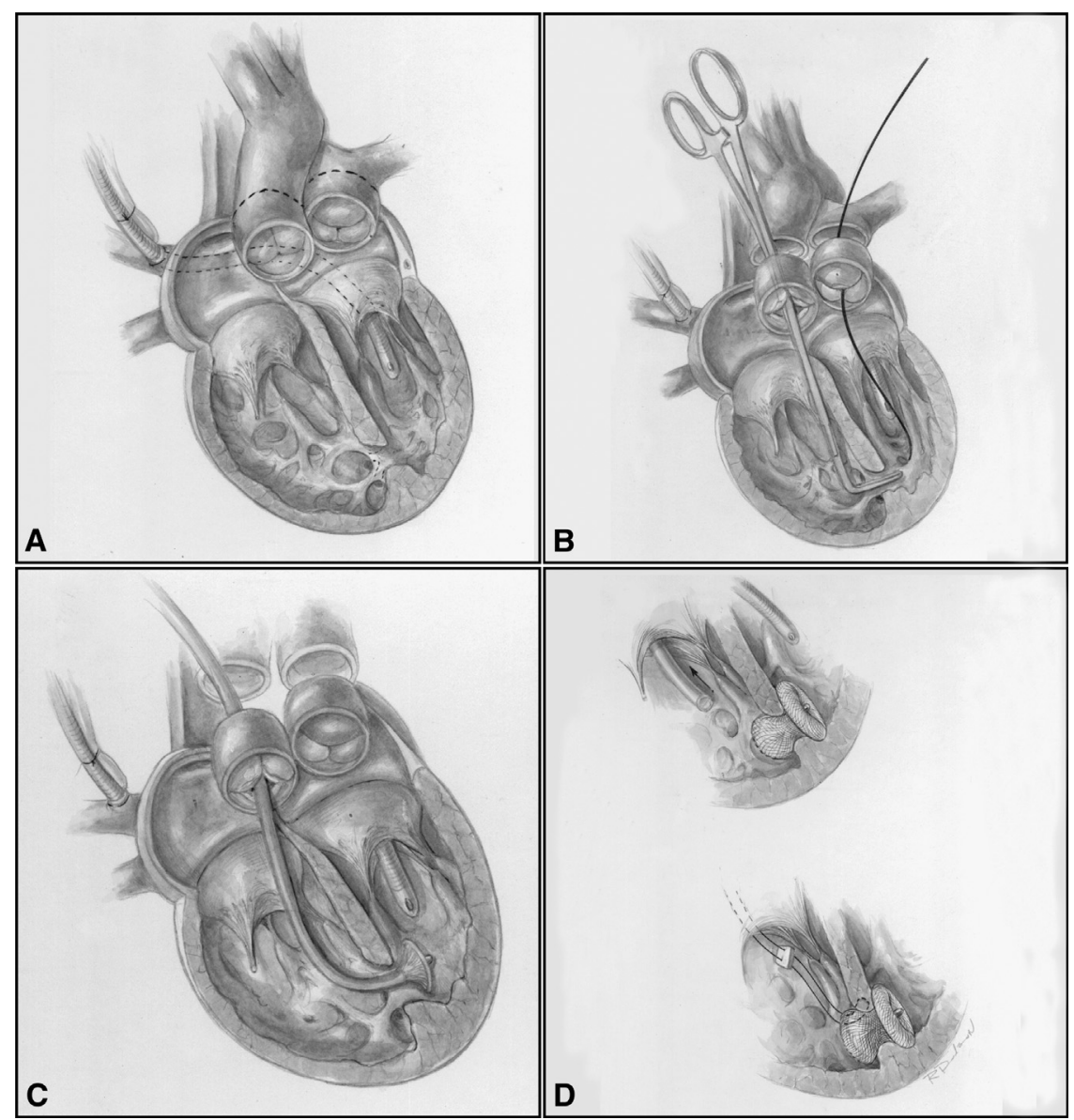

FIGURE 2. Trans-semilunar valve hybrid surgical technique for device closure of complex apical mVSDs. A, Transposed great arteries and complex apical mVSDs. B, Right angle clamp across the mVSD to snare a soft tip wire. C, Partially deployed ductal occluder device across the mVSD. D, Released ductal occluder device wedged in the mVSD and secured by a pledgeted suture.

\section{References}

1. Kumar K, Lock JW, Geva T. Apical muscular ventricular septal defects between the left ventricle and the right ventricular infundibulum. Diagnostic and interventional considerations. Circulation. 1997;95:1207-13.

2. Rodes J, Piechaud JF, Ouaknine R, Hulin S, Cohen L, Magnier S, et al. Transcatheter closure of apical ventricular muscular septal defect combined with arterial switch operation in a newborn infant. Catheter Cardiovasc Interv. 2000;49: 173-6.
3. Michel-Behnke I, Ewert P, Koch A, Bertram H, Emmel M, Fischer G, et al. Device closure of ventricular septal defects by hybrid procedures: a multicenter retrospective study. Catheter Cardiovasc Interv. 2011;77:242-51.

4. Neukamm C, Bjørnstad PG, Fischer G, Smevik B, Lindberg HL. A novel method of hybrid intraoperative catheter-based closure of ventricular septal defects using the Amplatzer PDA occluder. Catheter Cardiovasc Interv. 2011;77:557-63.

5. Baird CW, Stern H, Watts L. Left atrial hybrid closure of muscular ventricular septal defects with the Amplatzer device. J Thorac Cardiovasc Surg. 2009;137:779-80. 